\title{
"Remedios para la Nueva España". El México del siglo XVI a través de las informaciones enviadas a la Corona
}

\author{
M. ${ }^{a}$ Justina Sarabia Viejo \\ Departamento de Historia de América, \\ Universidad de Sevilla
}

Siguiendo la corriente historiográfica del arbitrismo, a modo de precedente sobre el Virreinato de la Nueva España, se analiza la correspondencia enviada a la Corona por Alonso de Herrera, Pedro de Meneses, Luis de León Romano, Francisco de Morales, Pedro de Ledesma y Francisco Gómez Triguillos de Silva entre 1544 y 1567. A través de estos seis corresponsales va planteándose una amplia gama de problemas económicos, sociales, políticos y religiosos y las posibles soluciones o remedios, a veces muy concretos y factibles. En estas cartas se da una visión panorámica del México de mediados del siglo XVI, en un proceso de cambio y crecimiento de la organización española.

\section{Introducción}

$\mathrm{Al}$ ir conociendo durante años la rica información sobre el primer siglo de presencia española en México, en este caso aportada por personas poco o nada conocidas en el ámbito oficial, frente a los grandes hombres, famosos por las biografías, estudios monográficos y otros trabajos, me pareció interesante sacar a la luz un conjunto de opiniones, críticas, propuestas, a veces verdaderos dictámenes, que los españoles residentes en aquel virreinato plantearon cuando la Nueva España se estaba conformando.

Para este artículo hay que valorar, y agradecer, la labor del ilustre polígrafo mexicano Francisco del Paso y Troncoso, cuyo Epistolario de la Nueva España $a^{1}$ recogió la mayoría de las cartas que aquí se comentan hace más de sesenta años, facilitando futuras investigaciones que muchos historiadores no han sabido, o querido, luego reconocer a través de las citas de esta obra.

La orientación propuesta se vinculaba, como precedente, con una corriente historiográfica de gran tradición, la del arbitrismo, que tan excelentes estudiosos ha tenido en la Historia de España, dando también cabida a los temas americanos, primero con la publicación de catálogos y

1 De 16 tomos, fue publicado por la Antigua Librería de José Porrúa e Hijos de México, entre 1939 y 1943 
"bibliotecas" y luego con trabajos sobre los temas, medios e incluso la propia figura del arbitrista, pero siempre referidos al siglo XVII. ${ }^{3}$ En la centuria ilustrada, el proyectismo será otra línea interesante para estos análisis de la situación política y económica de España y sus posesiones americanas. ${ }^{4}$

Centrándonos en el ámbito mexicano del siglo XVI, todavía se entremezclan intereses casi medievales, que buscan la gloria y el triunfo militar personal, con otros más pragmáticos, orientados hacia el desarrollo del virreinato, sus habitantes y sus riquezas, desde una visión occidental en lo político y en lo económico. A través del género epistolar, estos autores trataron de ofrecer a la Corona su visión personal, a veces como premisa para proponer a continuación diversos acuerdos, monopolios o capitulaciones, o conseguir cargos y premios, a cambio de aumentar las rentas reales y desarrollar los diversos sectores económicos novohispanos que por entonces eran inexistentes. Quizás tratando de dar mayor fuerza a sus argumentos, los corresponsales que se tratan a continuación usan mucho la palabra remedio, que luego será una de las más empleadas por los arbitristas.

\section{Alonso de Herrera}

No se tienen noticias sobre los orígenes y actividades anteriores de este hombre, que fue uno de los que más tempranamente mostró interés por las cuestiones económicas y que ha pasado a la Historia del México colonial por proponer el fomento de dos productos tan distintos como la cerveza y la hierba pastel, un tinte de color azul que se producía mucho en la región francesa de Toulouse. En cuanto a la cerveza, él informaba en su carta de 1544 sobre la consumición de esa bebida por españoles e indígenas, pese a que todavía se cultivaba allí poco trigo y cebada:

2 Después de los trabajos de Miguel Colmeiro y Penido, hay que citar la excelente puesta al día de Correa Calderón, Evaristo:Registro de arbitristas, economistas y reformadores españoles (15001936). Catálogo de impresos y manuscritos. Madrid, 1981, y la aportación de Martínez de Salinas

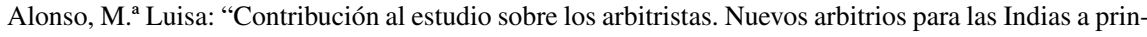
cipios del siglo XVII”. Revista de Indias, Vol. L, n. ${ }^{\circ}$ 188, Madrid, enero-abril de 1990, págs. 161-169.

3 Entre ellos los de Domínguez Ortíz, Antonio: Política y Hacienda de Felipe IV. Madrid, 1960; Muñoz Pérez, José: "El comercio de Indias bajo los Austrias y los tratadistas españoles del siglo XVII". Revista de Indias, n. ${ }^{\circ}$ 68, Madrid, 1957, págs. 209-222 y Vilar, Jean: Literatura y economía: la figura satírica del arbitrista en el siglo XVIII. Madrid, 1973.

4 Muñoz Pérez, José: "Los proyectos sobre España e Indias en el siglo XVIII: el proyectismo como género". Revista de Estudios Políticos, n. ${ }^{\circ}$ 81, Madrid, 1955, págs. 169-195. Almarza, Sara: Pensamiento crítico hispanoamericano: arbitristas del siglo XVIII. Madrid, 1990. 
"llegado a esta cibdad de México visto por el virrey a quien venía sometido (el asiento para fabricar esa bebida) lo aprobó como cosa de que la tierra tenía necesidad por la falta de vino y aceite que en ella hay sintiendo que era cosa en que podía ser servido Su majestad y así he asentado en esta ciudad una bracería [del francés brasserie] para hacer cerveza donde se ha comenzado a hacer e hay buen despacho en la que se hace aunque por la esterilidad del año e haberse helado los panes no se ha hecho tal como se hará acudiendo los años; españoles la beben de cabsa que el visorrey por dalla a entender, la bebe ordinariamente e por favorecer la hacienda que no ha sido poco menester según lo que abunde el tercio de derechos que della lleva e desta cabsa muchos la tratan mal y tienen manera como otros no la beban; los naturales de la tierra la tienen por mejor que sus pulques; hase vendido a ocho reales el arroba por la falta de trigo e cebada que hay: con el tiempo encaminando Nuestro Señor el año saldrá más barato ...". ${ }^{5}$

A continuación describía, con las mejores previsiones económicas, el futuro de esa explotación, que también redundaría en beneficio de los bienes de propios de las ciudades y pueblos novohispanos, como él sabía que ocurría en Flandes:

“... hasta hoy está una caldera asentada en esta ciudad [de México] e segund la mucha tierra e poblazones que en ella hay se pueden asentar cient calderas: a lo que parece por lo poco que hasta agora se ha hecho en ésta por no haber trigo ni cebada, créese que valdrá cada año cada caldera más de mil pesos a vuestra majestad, y poniéndose la orden que se requiere y dando vuestra majestad el favor nescesario a ello como por todos fuese bien tratado e aprobado sin el daño que hoy se rescibe, por el contrario y para ello si vuestra majestad fuese servido aprovecharía mucho hacer alguna merced a los propios desta ciudad de lo que resultare desta hacienda porque acá han dado a entender flamencos y otras personas que han estado en Flandes que este derecho de las cervecerías es de los propios de los pueblos e cuando a vuestra majestad alguna nescesidad se le ofrece deste derecho le hacen servicio". ${ }^{6}$

Los trabajos de Jean-Pierre Berthe han seguido la actividad de Herrera en las dos facetas que intentó desarrollar, siendo mucho más compleja la relación del español con el proceso del cultivo del pastel, como abreviadamente se llamó a esta planta. Este informante fue factor de dos alemanes, Enrique Ynguer o Einger (ex factor de los Welser en Venezuela) y Alberto Cuon, que habían firmado un asiento con Carlos I para explotar este colo-

5 El autor de la carta se refiere a don Antonio de Mendoza, primer virrey novohispano, que gobernó de 1535 a 1550, y no cabe duda de que exagera al afirmar que los indígenas de Nueva España preferían la cerveza a "sus pulques", con el fin de demostrar que los habitantes de todas las razas se habían aficionado a la bebida obtenida y distribuida por él. Archivo General de Indias (en adelante AGI), México, 76. Alonso de Herrera al rey. México, 15 de mayo de 1544. Reproducida por Paso y Troncoso, F. del: Epistolario ..., T. IV, n. ${ }^{\circ}$ 222, págs. 76-78, y en concreto pág. 77.

6 Ibidem. 
rante por un plazo de cincuenta años, a partir de $1535,{ }^{7}$ llevando simientes y trabajadores especializados de Francia y Flandes, además de comprar herramientas, animales de carga y esclavos negros para trabajar en los campos y en la delicada recolección de la hierba tintórea, en la que se incluirían también indios tributarios del área de Veracruz desde $1537 .{ }^{8}$

Cuando Herrera escribe, por tanto, ya se tenía una información de varios años sobre la explotación, y de nuevo hay que juzgar críticamente las afirmaciones recogidas en la carta sobre las posibilidades económicas del asiento, claramente deficitario según las cuentas de la Real Hacienda de 1537 a $1545 .{ }^{\circ}$ Afirmaba él:

"En lo que toca a lo del pastel ha de saber Vuestra Majestad que acá se da muy bien y habría lugar para hacerse toda la cantidad que quisieren despachar, así para estas partes de acá como para los reinos de Castilla e otras partes y en toda perfeción como todas las otras cosas acá responden, y así en esta cibdad y sus términos han comenzado a hacer casas e obrería de paños en que hay hasta hoy tres tintes asentados donde se spera en lo que más se hará, tener mucho despacho el pastel". ${ }^{10}$

Herrera indicaba las causas y personas que habían impedido el desarrollo de la explotación, con apellidos tan conocidos como el del contador real Rodrigo de Albornoz, que quería ocupar las tierras del asiento para trasladar allí un ingenio azucarero que tenía en Cempoala. Aunque se afirmaba que los indígenas dedicados a este cultivo estaba exentos de tributar a cambio de ese trabajo, que era más benigno que el del azúcar, los propios naturales contradijeron a Herrera en 1547, al denunciar ante el visitador general Tello de Sandoval a los españoles que dirigían la obtención del pastel, acusándoles de exigirles tributos en otros productos, de robarles e incluso de molestar a sus mujeres. ${ }^{11}$

El Consejo de Indias respondería en 1550 exigiendo las cuentas a Alberto Cuon, a través de la Audiencia de México, y el nuevo virrey Luis de Velasco se encargó de revisar esas cifras por medio de los oficiales reales y de la visita encargada a Diego Ramírez en 1552, que incluyó los pue-

7 Berthe, J.-P.: "El cultivo del pastel en Nueva España". Historia Mexicana, vol. IX, n. 3. México, enero-marzo 1960, págs. 340-356. AGI, Contaduría, 672. Traslado del asiento firmado entre la Corona y los alemanes Ynguer y Cuon "sobre la cría y beneficio del pastel y azafrán”. Belpuche, 27 de marzo y Barcelona, 30 de mayo, ambos de 1535.

8 Sobre los pueblos que trabajaron el pastel entre 1537 y 1545, véase AGI, Justicia, 1023, N. ${ }^{\circ} 1$, R. $^{\circ} 5$ y AGI, Contaduría, 672.

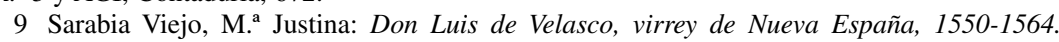
Sevilla, 1978, págs. 414-417. Herrera al rey.

10 AGI, México, 76 y Paso y Troncoso, Epistolario ..., T. IV, n. ${ }^{\circ}$ 222, págs. 77-78. Alonso de 
blos que tributaban en pastel. El máximo tribunal del Virreinato, a través de su fiscal, llegó a acusar de negligencia en relación con el asiento a su factor Alonso de Herrera que, después de varios años sin escribir, volvió a tomar la pluma para defenderse, indicando tres motivos principales como causantes del descenso de la producción: las epidemias de 1545-1546 y su mortandad entre los indígenas, las nuevas tasaciones realizadas en esos mismos años y el desvío de la mano de obra adjudicada al asiento para trabajar en la construcción de monasterios.

En 1556 el Consejo volvió a intervenir ordenando una probanza que trataba de demostrar el incumplimiento de los acuerdos y los malos tratos contra los indios. ${ }^{12}$ Los años siguientes generaron una serie de informaciones, protestas indígenas y nuevas tasaciones mediante la conmutación del tributo en este colorante por maíz, hasta que en 1563 se abandonó definitivamente la explotación que todavía estaba en activo. Las motivos finales que trataron de explicar este fracaso fueron el clima excesivamente húmedo, la poca preparación técnica de los que dirigieron el trabajo y los problemas con la mano de obra, que confluyeron en un producto de baja calidad, incapaz de competir en los mercados europeos con el pastel tolosano o de otras zonas productoras europeas. Es curioso que en la misma fecha en que se paró este asiento, Pedro de Ledesma, otro de los informantes que se analizará después, todavía aseguraba que:

“... si no ha habido provecho de lo que acá se hace [de pastel] ha sido por falta de quien lo tiene a cargo porque a la lengua (sic) del agua de la mar del norte se puede sembrar en parte donde baja sin peligro de dañarse y a poca costa". ${ }^{13}$

\section{Pedro de Meneses}

Es conocido el texto que envió en $1552,{ }^{14}$ aprovechando que venía a la corte Francisco López Verdugo, regidor de Oaxaca. En él se definía como "conquistador y poblador de los primeros, que siempre he estado y residi-

11 AGI, Justicia, 1023, N. ${ }^{\circ}$ 1, R. ${ }^{\circ}$ 5. Los indios de Jalapa, Coatepec, Xicochimalco, Xalacingo, Naolingo, Tlacolula, Xilotepec y sus sujetos al visitador Sandoval. Mayo de 1547.

12 Ibidem. Probanza ordenada por el licenciado Agreda. México, 23 de abril de 1556. AGI, Indiferente General, 1213. El fiscal de la Audiencia de México al licenciado Agreda. México, 20 de mayo de 1556.

13 AGI, México, 168. Capítulos que dirige al rey Pedro de Ledesma. México, 1563. Incluido en Paso y Troncoso, Epistolario ..., T. XV, n. ${ }^{\circ} 858$, págs. 74-75.

14 AGI, México, 168. Paso y Troncoso, Epistolario ..., T. VI, n. ${ }^{\circ} 346$, págs. 146-153. La carta está fechada en 27 de febrero de ese año. 
do sin haber vuelto a mi patria al cabo de treinta y dos años, donde me han nacido barbas y canas". Gracias a esta carta y al Diccionario de conquistadores recopilado por Víctor M. Álvarez, ${ }^{15}$ puede trazarse su biografía desde el nacimiento en Talavera de la Reina (Toledo): hijodalgo, nieto de Joan de Carvajal y doña Elvira de Toledo e hijo de Pedro Xuárez de Meneses y doña Leonor de Guzmán, casado con mujer hijadalgo, hija de Luis de Soto y parienta del gobernador de Cuba Diego Velázquez. Ocupó cargos en Guatemala y la costa de la Mar del Sur, apareciendo como visitador y en otros puestos de justicia, desde los cuales pudo observar los cambios del territorio mexicano con la idea de presentarse ante el rey para dar su opinión sobre diversos aspectos. Su mentalidad de hombre de la conquista, no exenta de resentimiento por las injusticias que sufría, le llevó a incluir en la carta un párrafo que recoge la actitud de este grupo de españoles a la espera de premios y cargos en la Nueva España:

“... débelo haber hecho el Señor [las injusticias] porque yo no lo merezco ni otros muchos que aquí hay que han servido a vuestra magestad y han medrado poco porque los que acá han venido recibímoslos como hombres y obedecémoslos como a dioses; varones tiene vuestra magestad y leales vasallos hijosdalgos y de todas las otras generaciones en quien se puede confiar esta gobernación, por su lealtad y bondad escogidos, y que si es menester vendellos o empeñallos no dirán que no, porque tienen gran deseo de salvar su ley y servir a su rey y han sido desdichados en estar vuestra majestad en guerras y trabajos, y por esta causa no ha dado asiento en lo que tanto conviene a su real servicio y al bien general de todos.". ${ }^{16}$

Al no conseguir viajar a la corte en ese largo tiempo, cercano a los treinta años, Meneses decidió mandar desde Puebla de los Angeles una detallada información de los asuntos que le preocupaban, en la que especificaba la necesidad de que los problemas se resolvieran en aquella tierra, sin tener que llevarlos ante el Consejo de Indias:

"Lo segundo que Vuestra Magestad al gobernador que viniere y visorrey a gobernar en vuestro real nombre le de facultad e instrucción por donde se rija porque las cosas de acá son varias y tienen necesidad de enmendarse acá y no remitirse allá porque la dilación las daña asi por el tiempo como por la distancia de camino dando su real orden para que con sus oidores y Consejo acordados, viendo el pro y contra, den el medio que vieren ser necesario y no como vemos que todo de muy repensado se ha venido a perder la mejor cosa, y se va perdiendo, que hay en el mundo, ques esta Nueva España, por no atenderse allá ni acá por las novedades y mudanzas que de allá vienen y acá es imposible entenderse.".

15 México, octubre de 1975. 2 tomos. T. II, n. ${ }^{\circ}$ 677, págs. 352-355.

16 Carta de 27 de febrero. Véase nota 14. 
Los temas eran varios, todos ellos de plena actualidad en esas fechas. Así, teniendo en cuenta el momento de efervescencia provocado por la aplicación de las Leyes Nuevas, se manifestaba claramente a favor de la concesión del reparto general de la tierra entre los españoles, como premio pero para trabajarlas y dar una parte de ese rendimiento a la Corona a modo de pago, frente a lo poco valioso que resultaba el territorio bajo la administración directa de los diversos cargos de otorgamiento real. Por eso especificaba, poniendo como ejemplos de decadencia a Colima y Zacatula:

“... dando cada uno [de los conquistadores y pobladores] conforme a sus servicios y calidad y mandando que cada uno siempre coja frutos que en las tierras se dieren conforme a la calidad dellas y que tome vuestra majestad en ellos y sobre sus pueblos la parte que le pareciere questá en razón, como nuestro rey y señor y arriende sus rentas conforme a los reinos de España y que asistan como mayordomos, cada uno acuda con lo que perteneciere a vuestra majestad y no habrá la perdición que hay ni el poco provecho que se sigue destar en corregidores y fator y tesorero y en una behetría vuestra real hacienda que sería no acabar habello describir porque por experiencia vemos quel pueblo questá en vuestra real cabeza no renta nada con ser cabeceras que podrían dar cuatro doblado ......". ${ }^{17}$

A lo largo de esta carta se observan fuertes críticas sobre la labor de los religiosos, igualmente desconocedores de la realidad novohispana según Meneses. Mientras para él los indígenas "como gente nueva han menester ley nueva amorosa y mezclada con el azote como crían a los niños en las escuelas" — nótese el sentido paternalista y la visión de inmadurez de los naturales que expone el autor del texto-, los frailes eran "obedecidos y servidos" por ellos debido a su mayor autoridad pero, a continuación, opinaba contra la presencia y actividad continua del clero regular junto a los poderes en vez de dedicarse a la evangelización, “... no se entremetiendo en otras cosas tocante a las gobernaciones, casos de justicia y determinaciones y tasaciones ...”.

Más adelante, al tratar de justificar el trabajo indígena en las minas como no pernicioso, arremetía de nuevo contra los religiosos, personificados en fray Bartolomé de las Casas, llegando a escribir con toda dureza:

“... lo que dicen de los esclavos [indios] pudo ser haber hierro [de marcar] en los principios y aunque si se informase de las personas xristianas y doctas como han buscado algunas simples [en] especial el obispo de Chiapa y sus consortes, buscando los medios o malos principios, informaron y aliaron consigo algunas gentes que tenían poca noti-

17 La misma carta de 27 de febrero de 1552 . La cursiva es mía. 
cia y no podían informar verdad porque no lo sabían ... y si el saliera electo por Dios como hemos visto su cobdicia, diéramos crédito a su obra; pruebe vuestra majestad a dalle el arzobispado de Toledo ..." ${ }^{18}$ — hasta advertir— “ ... y siendo así cese el engaño pues tenemos los pies en una de las mayores y mejores cosas que hay en el mundo si se asienta y si no en la peor y en el que más aina se consumiera y acabara ...".

Frente a estos problemas, Meneses se muestra defensor de la organización indígena precortesiana, pero quizás más por mantener esas críticas hacia el poder religioso que por convencimiento. Frente a las autoridades españolas, como alcaldes y regidores, y a la manipulación de los frailes en la sucesión de los cargos indígenas, opinaba:

"Lo que conviene a los naturales es que vuelvan al arte que tenían en sus señoríos y gobernación, acudiendo con lo que fueren obligados a sus tributos, conforme a sus tasaciones, quitalles las gobernaciones puestas y las alcaldías y regimientos por consejo de religiosos porque los señores naturales están arrinconados y se me han quejado muchas veces de las elecciones que se hacen, y que como premite (sic) vuestra magestad y su Real Consejo que sean desposeidos de sus señoríos y dados a muchachos criados de los religiosos y que en tres días aumentan sus haciendas, por aquellas vías hacen sus casas y a sus parientes cada vez que los mudan renuevan los trabajos y otros subsidios ....". ${ }^{19}$

Pero no siempre daba esa visión positiva del indio. Al tratar de un tipo de trabajo tan necesario como el de los intérpretes o lenguas indígenas, criticaba a los que actuaban como tales por sus "cohechos y robos" en los pleitos entre naturales, perjudicando a los de su propia raza. Por eso elogiaba cómo el virrey Mendoza, los oidores Tejada y Ceynos y el visitador general Tello de Sandoval habían quitado a varios de ellos e incluso azotado a otros, y solicitaba que "hubiese personas dotas (sic) en su lengua, xristianos como los hay que de prima instancia entendiesen [el] porqué de los pleitos desta tierra entre los naturales, como es restitución hecha después que vuestra majestad posee estas partes, es necesario averiguar de plano sin dar lugar a malicias, por questos pueden poco y llévanles lo que no tienen;".

Lógicamente, le preocupaba mucho el desarrollo económico que podía alcanzar la minería de oro y plata, que él veía con futuro si se fomentaba el trabajo indígena en los nuevos centros recién descubiertos. Describía Taxco y su rápido crecimiento como ciudad minera y dedicaba varias líneas a demostrar que los indios no sufrían ningún riesgo de enfermedades y de ahogo en esas actividades laborales.

18 Ibidem.

19 Ibidem. De nuevo la cursiva es mía. 
En el párrafo de despedida, volvía a expresar su pesimismo por la situación en que se veía, exagerando las tintas:

“... yo he escrito como hombre deseoso de acertar aunque más quisiera ir en persona; vuestra magestad recíbalo del siervo como poderoso príncipe y descargue su real conciencia y dé asiento, que ya no cabemos en esta Nueva España con nuestra labranza $y$ crianza, que de todas partes nos cercan trabajos como responden vuestros oidores que allá van, que por no ver perder la tierra se van". ${ }^{20}$

\section{Luis de León Romano}

Este caballero, natural de Roma, pudo pasar a la Nueva España en 1537 por concesión expresa de Carlos I, aunque parece ser que ya había estado allí de 1530 a $1532 .{ }^{21}$ Hasta su muerte en la ciudad de Antequera (Oaxaca) en 1557, ocupó varios cargos en Michoacán, Oaxaca, Puebla y la propia capital mexicana, de la que llegó a ser proveedor mayor; en sus idas y venidas adquirió una gran experiencia y vivió los problemas de la población indígena, dedicando parte de su legado a la construcción de un colegio seminario para religiosos - finalmente dominicos después de un intento con los franciscanos- que sería el de San Luis de Francia, en Puebla. ${ }^{22}$

Desde la ciudad de México, donde residiría durante los primeros años del gobierno virreinal de Luis de Velasco, escribió al príncipe Felipe, entonces regente, varias cartas, entre ellas la que aquí se comenta. ${ }^{23}$ Por su conocimiento, adquirido in situ en lugares de distintas culturas indígenas, interesa su dictamen, bastante parecido por cierto al de Pedro de Meneses en su punto de vista de valorar la época precortesiana y criticar la organización española respecto a los naturales, por sus consecuencias negativas. Un largo párrafo sin desperdicio lo iba comentando:

"Las repúblicas destos naturales me paresce están sin orden y policía alguna, así en lo que toca a su conversión como a lo que conviene a la conservación y augmento dellos, y según paresce esto lo ha causado habérsele pervertido su gobernación tan al

20 Ibidem.

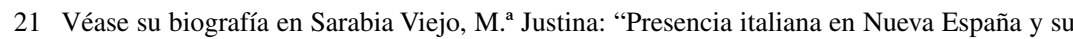
conexión sevillana (1520-1575)”. En Presencia italiana en Andalucía, siglos XIV-XVII, págs. 427-462. Sevilla, 1989, págs. 447-448.

22 Sarabia Viejo, Don Luis de Velasco, ..., págs. 204-206.

23 Fechada en México, el 20 de abril de 1553. AGI, México, 168 y reproducida por Robert Ricard en "Un document inédit sur la situation du Mexique au XVI siècle". Miscelanea de estudos em honra de Da. Carolina Michaëlis de Vasconcellos. Coimbra, 1930; también la incluye Paso y Troncoso (Epistolario ..., T. VI, n. ${ }^{\circ}$ 348, págs. 156-161), pero erróneamente fechada en 1552. 
contrario de la que solían tener, la cual cierto para el ser dellos, era la mejor que nunca nación tuvo, dejado lo de sus ánimas, y por el descuido que con ellos se ha tenido en gobernar la menor parte destas repúblicas y tratar en sus pleitos y negocios que es nuestra nación y dejar la mayor sin dar orden ni policía alguna y haber dado más libertad de lo que a su ser convenía y puesto entre ellos moneda diferente de la que solían tener que era visto y vestido que no se podía thesaurizar como la que al presente usan, y haberse gobernado debajo de una ley dos naciones tan diferentes como es de hombres a niños".

Después de esa opinión final, llena de un paternalismo tan negativo, cargaba todavía más las tintas al comentar los resultados cuando escribía:

"Andan al presente entre los naturales dellas y entre nosotros los frenos trocados de arte que los que habían de mandar son mandados y los que nos habían de gobernar no gobiernan, y los que habían de trabajar y cultivar las tierras no trabajan y los oficiales han dejado sus oficios, y todos se han dado al trato de holgar y mercadear en tanta manera que van como hacto (sic) de cabras sin pastor y dejado lo que solían hacer para su conservación al presente no entienden en otra cosa sino en sus vicios, y desto muy poderoso señor, ha resultado y resulta gran daño porque los bastimentos y lo demás necesario para su conservación han subido en ecesibos precios que casi no se hallan por dineros de más de otros notables daños y los vicios que habían de ser disipados prevalecen más que nunca; cierto con tanta disolución, confusión y desorden, no sé en lo que han de parar estos miserables. Los años pasados han sido prósperos de bastimentos, y si con ellos tiene esta nación la falta que digo, qué será dellos subcediendo lo contrario, perecerán de hambre y de pestilencia como suele acontecer."

Apoyaba León Romano en su escrito el que se impidieran pleitos y retrasos en la administración de la justicia, siempre alegando que asi se evitaban muchos problemas, y ponía como ejemplo:

"Si esta nación por fuerza de armas expugnaran nuestros reignos y nos hicieran guardar sus leyes ordenanzas y costumbres en que aumento viniera nuestra república: cierto creo que se destruyera y asolara. Si sus leyes a nosotros fueran dañosas las nuestras a ellos no han sido ni serán provechosas por ser nación de poco juicio y menos ser, y si Montezuma (sic) rey destos naturales conservó estos reinos con sus leyes, y siendo hombre más inrracional (sic) que de razón con grandísimo augmento y policía hartos de bastimentos, mejor lo conservaría un católico xristiano conformándose con sus leyes y de las nuestras y siendo solo en el gobierno, y no con tantos coadjutores y gobernadores como al presente hay".

Más adelante, proponía una solución semejante a la de Pedro de Meneses, por considerarla un mal menor:

"Demás de lo que digo conviene dar a esta nación asiento en sus costumbres y algunas de las nuestras las que fueren necesarias y ponellos debajo del yugo de sus centuriones como solían estar que les hagan hacer lo que a ellos conviene apremiándo- 
les a ello porque de su voluntad y para sí y sus hijos nunca han hecho ni harán sin premio cosa que les convenga, porque esta nación ha sido y es de tal condición; y reformar los oficios necesarios en sus repúblicas de los cuales al presente carece, y desta manera terná esta nación lo que agora les falta y no quedarán tan destruidas y perdidas por falta de gobierno como al presente están; piden estos naturales ley en que vivan y no hay quien se la dé por no haberse entendido su gobernación hasta agora ...... ${ }^{24}$

Al tratar otro aspecto que le preocupaba, el de los problemas de abastecimiento, León Romano contraponía de nuevo las dos repúblicas, indicando que ambas debían mentalizarse para trabajar ante el aumento de la población española, del cual daba cifras, que cada año iba planteando mayores problemas para abastecerse de lo más necesario:

"Esta ciudad de México y las demás desta Nueva España van en augmento grandísimo de gente de nuestra nación y en mayor necesidad de bastimentos que apenas se pueden sustentar y viven muchos de los vecinos dellas en mucha calamidad e miseria por que casi no lo hallan a comprar con dinero, los unos por no haber de quién como solía, los otros porque aunque lo quieran sembrar no tienen posibilidad, ni dónde, y esto resulta de lo que arriba digo, porque al tiempo que estos naturales tenían concierto en su gobernación los unos y los otros no carecían de lo necesario; si al presente que moran en esta ciudad doce o quince mil ánimas pasa lo que digo, qué será en lo de adelante cuando sean treinta mil; paréceme que por vía ninguna se podrán sustentar sin grandísimos daños e inconvinientes. ... Necesaria cosa es questas ciudades se provean como las demás destos reinos, dándoles las aldeas que convinieren en sus comarcas sin tener respecto (sic) al perjuicio de los indios sino a la conservación de ambas repúblicas, pues sé que no lo hay ni faltarán sitios ni tierras baldías para ellas ni gentes que las pueblen, y proveyéndose esto no carecerá México ni las demás ciudades de lo que al presente carecen ni irán los españoles por los pueblos de los indios vendiendo agua por vino y vinagre con agua ni usarán los tratos ilícitos como al presente usan, ... y dando la orden que he dicho se dividirán estas repúblicas de manera que la una vivirá sin dar molestia ni vejación a la otra que es lo que conviene, y a ambas no faltará lo necesario; esto conviene se provea con brevedad porque habiendo en ello dilación andan los negocios desta tierra al presente en tal término que podrían parir estas naciones algunos hijos que pocos sirvieran a sus padres ni menos a su magestad, porque de tan ruin preñez no se puede esperar sino mal parto". ${ }^{25}$

Este informador anunciaba con agudeza el problema que iba a constituir la primera generación criolla que él veía criarse en las calles y sin un futuro claro, pero su única solución era cuidar las defensas, sin pensar en aspectos educativos y laborales más constructivos:

24 Ibidem.

25 Ibidem. Las cursivas son mías. 
"Los niños mozos desta nuestra república se crían sin virtud ni disciplina alguna, si no es la del tianguez o plaza de México y en otros vicios y aunque los padres les quisieren dar alguna, no hay en qué ejercitarlos; van en augmento grande: no sé daquí a pocos años a que han de parar por no tener salida ni ejercicio virtuoso en qué ocuparlos, parésceme qué en el tiempo que digo su majestad terná pocos amigos en los mozos que al presente hay como en los que de hoy más se criaren, ansí de los de nuestra república como de los naturales y por evitar lo que desto podría subceder sería bien que mandasen hacer algunas casas fuertes y se proveiesen de las cosas necesarias y no se debería tener tanta confianza que diese ocasión a los súbditos que hagan lo que no deben porque las armas siempre suelen traer consigo la paz".

El caballero Romano — como fue a veces denominado- defendía la autoridad y la experiencia del virrey como máxima jefatura en aquel territorio, debido a las peculiaridades novohispanas, considerando que había de tener una total autonomía para "que haga la ley conforme a la nación e tiempo y que a los negocios y delitos que se ofrescieren no de plazo ni traslado, mas que castigue con el rigor que a los súbdictos conviene, pospuesta toda tela de juicio como antiguamente se usaba". Llegaba a opinar sobre los errores pasados y la elección de futuros virreyes, defendiendo siempre que éstos, así como los miembros de organismos metropolitanos tan importantes como el Consejo de Indias, fueran personas experimentadas en asuntos de gobierno y administración indianos:

"La gobernación desta república hasta agora, ..., no se ha entendido por ser diferente de todas las demás que entre los humanos hay como he dicho, porque los que han gobernado y gobiernan han corrido con el tiempo y en algunos negocios fue provechoso y en otros no tanto y si los de allá como los de acá los han proveido por relación de personas que no entendían de lo que trataban ni era de su profesión de que no ha resultado ni resulta a este reigno poco daño. Los yerros que aquí se hacen en breve se remedian, los de allá no sin grandísimo daño. Si el que nos gobierna yerra teniendo presentes los negocios qué harán los que se proveyeren de allá y por relación de los que digo, porque lo que parece ser útil y provechoso para estos miserables cuando llega acá por la dilación del tiempo es dañoso porque no se compadece que el médico esté tan ausente del enfermo como está este reino dél: gobierne, poderoso señor, como digo un hombre solo e yerre porque los negocios desta tierra son de tal calidad que errando los acertará por tenerlos presente" ${ }^{26}$

\section{Francisco de Morales}

Otro "autor epistolar" prolífico de la década de los sesenta fue este abogado, que llegaría a ser relator de la Audiencia de México. A partir

26 Ibidem. 
de 1559 escribió varias cartas a fray Bartolomé de las Casas y a Felipe II — hasta cinco sólo en el mes de mayo de 1563- y todas ellas fueron de gran interés aunque en alguna alegó que "Desta Nueva España no trato cosa ninguna porque vivo en ella y no tengo oficio ni calor ni favor a qué atreverme". También se diferenciaba de los anteriores en que explicaba que no podía pasar a España para informar en persona por que estaba enfermo y podía morir en la travesía y por que era pobre y no disponía de dinero para ese viaje pero solicitaba una real cédula, y de paso algún cargo, que le diera orden y libertad de enviar a la Corona información "en lo de las Indias las cosas de su ynteresse real". ${ }^{27}$

En la carta al padre Las Casas, ${ }^{28}$ después de describirle los problemas en las áreas de Oaxaca y Puebla y en los conventos dominicos de ellas, se refiere a diversos asuntos de Guatemala y Chiapa, conociendo el interés del famoso dominico por esa zona; pero en los documentos de $1563^{29}$ aparece claramente una rica información sobre aspectos de fomento del virreinato. Así, en otra de esas cartas, fechada en 20 de mayo de ese año, trata varios asuntos económicos y sociales, entre ellos:

-Frente a los críticos de la concentración de tierras y ganados en manos de españoles,$^{30}$ le preocupaba más que esa ganadería guardada en las grandes dehesas de españoles no estuviera claramente legalizada y proponía "remedios" que beneficiarían tanto a la Corona como a esos poseedores de tierras, siempre sobre la base de la gran riqueza ganadera y sus óptimas posibilidades económicas, en comparación con la metrópoli:

“... y es el caso que las dehesas e sabanas e tierras que los españoles en las Indias poseen es cosa riquísima e de grande valor e aprovechamiento de renta porque hombres e vecinos hay en las Indias que poseen estancias tierras e dehesas de todos ganados, ques como un estado en España y ellos no dejan destar temerosos que en ello no poseen más de una figura de posesión a voluntad de vuestra magestad, mientras aquel ganado dura en la tal estancia porque en faltando ni habrá quien lo venda ni comprador que lo quiera, son más preciados los pastos e dehesas destas partes e más ricos fértiles de aguas yerbas leña e sanidad de todos quantos puede haber en el mundo e la carne de todo género el dia de hoy es de grande valor e aprovechamiento a causa de que los

27 Para un mejor conocimiento de este abogado, véase su Información de méritos y servicios fechada en México, 23 de enero de 1561 en AGI, México, 206, R. ${ }^{\circ} 3$, docs. 30 y 30a.

28 AGI, México, 96, R. ${ }^{\circ}$ 4. México, 1 de septiembre de 1559.

29 Véanse esas cartas en AGI, México, 97, R. 4.

30 Véase, por ejemplo, un párrafo del "Memorial de las cosas que han sucedido en la Nueva España , que conviene que Su Majestad remedie ...", anónimo y s/f pero anterior a 1555 ya que se refiere mucho al obispo de Oaxaca Juan de Zárate, fallecido en esa fecha. Paso y Troncoso, Epistolario ..., T. XV, n. ${ }^{\circ} 867$, págs. $125-136$. 
indios la gastan e la corambre lo mesmo, jamás en estas partes hay ni subcede en los ganados las morriñas y pestilencias en secas que suelen subceder en España e tiénense por mejores haciendas que las dehesas de La Serena e las demás de Extremadura pruébase que en tres dias que ha que las Indias se ganaron se han dado tanta e tan grande cantidad de ganados en todas ellas e se come e gasta más en una ciudad de Indias que en diez de España e porque podrían los vecinos agraviarse en decir que se les quita lo que poseen e también hacerse reacios en dejar las tierras e servir a su magestad con alguna suma paresce que convendrá que ante todas cosas los pastos e tierras e dehesas se den e declaren por realengas e de su magestad e del patrimonio de Castilla revocando cualesquiera títulos e ordenanzas en especial a los que tuvieren ganados en los términos de sus encomiendas y esto hecho y pregonado luego los dueños de ganados como sepan que hay facultad de vuestra magestad para que se les venda e dé título dello para que sin ganado e con ello las puedan arrendar e poblar e lo demás que convenga para su saneamiento, acudirán con el interés que bueno sea para vejarlos y compelerlos no viniendo luego a lo que convenga se les podrá imponer en lo criado e que se criare un tanto por cabeza y aun en la carne que se pesare e vendiere en las carnecerías e rastros, cobrar alguna cantidad repartida suelto a rata e justo es que pues acá no se sirve vuestra magestad de alcabalas ni servicios ni monedas foreras ni le dan otros aprovechamientos que en España sus vasallos e grandes le dan teniendo más antiguo e mejor derecho a lo que poseen que pues acá los españoles poseen lo mejor del mundo y están riquísimos e viven prósperos e sin vejación ni cuidado antes en toda nobleza llevando tributos de indios e minas de plata e los pastos e tierras que acá vuestra magestad tiene que le sirvan e reconozcan con lo que sea razonable y el que no quisiere dar luego dinero o no lo tuviere que lo imponga de censo sobre las tales dehesas y estancias que no faltará quien compre acá los tales censos e se vendrá a convertir todo dinero y este negocio y los demás son para que juez propio de vuestra magestad venido de España con grande poder lo ensaye y ejecute". ${ }^{31}$

-Pensando en la mejora de la Real Hacienda, siempre necesitada, aconsejaba emplear en el virreinato una moneda que mezclara la plata con otros metales, calculando en veinte millones la ganancia por ese cambio:

“... porque [en Nueva España] se hace de moneda e plata en ella dos millones de tostones e conforme a la liga que en España se echa tiene acá más valor un tostón que los de España ocho o diez maravedís e ciertamente los mercaderes que tratan en estas partes y en España según se tiene relación si quieren aprovechallos ... sino que de hecho luego se eche esta cantidad de liga e cobre e se cobren estos veinte cuentos porque vuestra magestad no tiene en la Nueva España renta que baste para pagar ..." los gastos, entre ellos las ayudas y premios a los conquistadores y sus descendientes.

-En cuanto a la aplicación de las Leyes Nuevas, y en contra de la postura mayoritaria de los españoles, proponía que se aplicase con rigor el capítulo ordenando quitar los indios encomendados y tributarios a los que

31 AGI, México, 97, R. ${ }^{\circ} 4$. 
los tuviesen sin ningún título, alegando únicamente que dependían, como sujetos y estancias, de otros pueblos o que las encomiendas les habían sido entregadas por tenientes de gobernadores, no autorizados para hacer estas concesiones legalmente. Y por eso opinaba que:

\begin{abstract}
"Vuestra magestad sobre estos casos mande que se haga especial, larga y particular averiguación y que las tales personas por pregón y debajo de grave pena declaren ante el juez de vuestra magestad y su Audiencia qué indios, pueblos, estancias y subjetos tienen y con qué título y esto hecho sumariamente y sin pleitos ordinarios, vuestra magestad se restituya en lo que es de su patrimonio real ....".32
\end{abstract}

Morales era consciente de que sus informaciones no siempre le ganaron la simpatía de los españoles residentes en México, que llegaron a desconfiar de estos "curiosos" dispuestos a escribir a la Corte reflejando sus opiniones y sugerencias. Según él, "es causa que [éstos, incluyéndose él mismo] sean odiosos y mal quistos, acusados y vituperados aunque sean unos santos".

\title{
Pedro de Ledesma
}

Su carta es uno de los textos emblemáticos en la búsqueda del fomento mediante remedios fáciles para el "engrandecimiento del país y aumento de la Real Hacienda", ${ }^{33}$ alegando que si se llevaban a cabo, "en pocos años y con no mucha diligencia y gasto podrían venir de los reinos extraños tantos dineros a los de vuestra magestad cuantos ahora salen, pues todas las cosas de valor y provecho que hay derramadas por el mundo las puede vuestra magestad tener juntas en la Nueva España y cargar de ellas naos como ahora se cargan para acá ...”. La fertilidad y posibilidades de las Indias eran otra vez destacadas por este informante.

A continuación detallaba los posibles elementos de ese cambio, mostrando en algunas líneas matices de un criollismo temprano, defensor de aquellas tierras:

- Impulso de los productos tintóreos de color azul, sin aludir a la grana, quizás por que su explotación ya estaba organizada en estas fechas,

32 Ibidem.

33 AGI, México, 168 y Paso y Troncoso, Epistolario ..., T. XV, n. ${ }^{\circ}$ 858, págs. 73-80. "Capítulos que dirige al rey Pedro de Ledesma, sobre las cosas que conviene proveer en Nueva España para engrandecimiento del país y aumento de la Real Hacienda”. C.1563. 
coincidentes con los últimos años del gobierno de don Luis de Velasco. Se concretaba en el añil - "que lo de esta tierra es mejor que lo mejor de Berbería"- y en el pastel o hierba pastel - "tan bueno como el de Tolosa" (Toulouse, en Francia) - y consideraba que el fracaso de ambos cultivos en una primera etapa se había debido a la falta de mano de obra especializada, en el caso del primero, y, como ya se ha indicado, a la mala gestión de los asentistas del pastel, pese a que éstos llegaron a trasladar desde Francia pasteliers especializados para enseñar a los indígenas las técnicas del cultivo. ${ }^{34}$

-Desarrollo de otras fuentes de riqueza, como plantar olivares con el fin de tener abasto de aceite y jabón, sacando un beneficio rápido de cien mil pesos anuales; producir vino "que se daría muy bueno, por la diversidad de temples y calidades de tierras que hay en esta Nueva España"; cultivar semillas para fabricar posteriormente lino, algodón, ruán, paño y seda, ahorrando con ese desarrollo textil unas cantidades importantes, e incluso fomentar la especiería y las drogas medicinales, para lo cual recordaba los asientos firmados en 1558 con don Francisco de Mendoza, hijo del primer virrey novohispano, con el fin de obtener en aquel territorio pimienta, canela, clavo, jengibre, sándalo y ruibarbo y que, pese a su fracaso, consiguieron buenas calidades "porque el jengibre ... se da tan bien como en Calicut, y el ruibarbo lo mismo". ${ }^{35}$ Pedro de Ledesma parecía no tener en cuenta -o quizás desconocía- la oposición real al desarrollo de estas fuentes de riqueza en el Nuevo Mundo.

- La mejora del estado financiero es otro aspecto de capital importancia desarrollado por este informante con la mayor extensión y detalle. Inicialmente se trata el preocupante tema de la saca de moneda, al que culpa del estado de debilidad y parón económico en que está el virreinato,

"porque con valer la hechura de la plata labrada en esta tierra a excesivo precio acaece querer vender la plata labrada a peso de sola ella, y no haber quien la compre ni las demás alhajas de casa aunque se den a menos precio: vienen desta falta de moneda tantos males que serían largos no sólo de escribir más aún de contar: todo esto causa la maldita y rabiosa hambre de enviar dineros a España por la codicia del retorno, y si en ello no se pone límite no sólo esta tierra no se pueda sustentar mucho tiempo, mas España se nescesitará de nescesidades extremas ...".

34 Véase Sarabia Viejo, M. ${ }^{a}$ J.: La grana y el añil. Técnicas tintóreas en México y América Central. Sevilla, 1994, págs. 23-27.

35 Sarabia Viejo, M. ${ }^{a}$ J.: "Posibilidades de la especiería mexicana en la economía mundial del siglo XVI". Andalucía y América en el siglo XVI. Actas de las Segundas Jornadas de Andalucía y América, 2 Ts. Sevilla, 1983, T. I, págs. 389-411. 
- La carestía de los precios, provocada por la dependencia respecto de los productos de la metrópoli, la unía a esa falta de moneda. Esa subida hizo que el coste de la vida se multiplicara por tres o por cuatro en pocos años, llegando a provocar escasez, que, según Ledesma, aumentaría "de aquí adelante questa tierra se pueble en gran manera". ${ }^{36}$

Y para apoyar esa autosuficiencia, valoraba la tierra mexicana como "la más fértil, de más baldíos y mejores temporales y más labradores que hay en el mundo; y los indios muy diestros de labrar la tierra con bueyes y arados y otros instrumentos de hierro de que ellos carecían ...". Con esta afirmación, claramente excesiva para 1563, trataba de afianzar sus recomendaciones, aunque la realidad laboral que se conoce fuera muy distinta para la mayoría de los indígenas a lo largo del siglo XVI.

Profundizaba aún más al afrontar la posible acusación de que, si se rebajaba el traslado de productos desde la metrópoli a Nueva España, el real erario sufriría las consecuencias, al bajar los ingresos de las aduanas y almojarifazgos, principales impuestos vinculados al tráfico ultramarino. La respuesta de Ledesma era que, al aumentar la colonia sus producciones propias, ello redundaría en una subida de los derechos correspondientes a la Corona, incluso por que esos productos podían venderse a los "reinos extraños". Toda una moderna teoría económico-monetaria, que nada conseguiría ante la fuerza del monopolio comercial indiano.

- La suspensión de futuros descubrimientos y entradas la consideraba una necesidad complementaria del punto anterior por la sangría monetaria que implicaba, llegando a argumentar que "no hay cabsa para que vuestra magestad deje perder lo ganado por ir con tanta costa a buscar lo que no ha perdido". Matizaba que si el rey quería poblar, convertir infieles o adquirir más riquezas, todo ello lo sacaría del propio Virreinato pues no debía

“tratar a la Nueva España como si no la quisiese más de por uno, porque, si por disiparla de moneda los mercaderes cada año vienen a cesar las minas por no poderse costear y por falta de esclavos o vienen a faltar los metales como cada día acaece, todo cesaba y no había cosa de que vuestra magestad pueda ser de ella servido".

Con esa protesta se ofrecía una visión negativa del futuro a corto plazo, si no se tomaban pronto las medidas necesarias por parte de Felipe II y el Consejo de Indias.

36 Véase la carta citada en AGI, México, 168. 
La extensa carta concluía con un párrafo que hoy llamaríamos de incompatibilidades para futuros gobernantes de México, cuya repetición y posterior inclusión en la Recopilación de Leyes de Los Reynos de Indias de 1680, sería una clara muestra de su incumplimiento. En él se detallaban las condiciones que debería reunir:

"El que hubiere de venir conviene sobre todo que sea desarraigado y despegado de todas las cosas de acá, recto y celoso del servicio de Dios y de vuestra magestad, apartado de torpes ganancias y siniestras cobdicias, sin pinta de parentesco ni cosa que se le parezca, porque los que están o pretenden permanecer, lo que a unos está bien a otros no les conviene como cuerpo de muchas cabezas de diversos pareceres que forzado ha de ser una ciega confusión, pero si no ha de ser tal, más valdría que la cosa se estuviere como está ....". ${ }^{37}$

La frase final ya muestra una clara desconfianza en la aplicación de las condiciones que proponía Pedro de Ledesma y puede aplicarse no sólo al aspecto concreto de los gobernantes sino para la recuperación económica del Virreinato imaginada por él a lo largo de la carta.

\section{Francisco Gómez Triguillos de Silva}

De origen ilustre, vinculado a la casa del rey, ya que su abuelo Ruy Gómez de Silva fue ayo de la emperatriz Isabel, ocupó en México cargos relacionados con la Real Hacienda, lo que da a sus cartas un tono de mayor especialización, ${ }^{38}$ que contrasta con sus repetidas citas de personajes y escenas bíblicas, en un estilo literario "apoyado en figuras y parábolas", según lo define él mismo.

Muestra una preocupación constante por depurar abusos, tanto de burócratas como de otras personas civiles y religiosas, alegando siempre su objetivo de mejorar los ingresos del real erario con una serie de cambios, pero también aprovecha para solicitar al final la concesión o la venta de uno o varios empleos públicos para sí mismo, lo que plantea dudas sobre la honradez de sus testimonios aunque se declare "desembarazado de cuidado y desnudo de bienes".

Uno de las cuestiones que le interesaba era la realización frecuente de almonedas o subastas de productos básicos como cacao, trigo, maíz o ropa,

37 Ibidem.

38 Cartas fechadas en 1 y 15 de marzo de 1567. Paso y Troncoso, Epistolario ..., T. X, números 582 y 584, págs. 172-175 y 177-197. 
en las cuales, en vez de pagar al contado se permitía ilegalmente el fiado, retrasando con ello la entrada de ese dinero en las cajas reales, a veces durante varios años, mientras los oficiales reales, e incluso los oidores de la Audiencia de México, se enriquecían en poco tiempo. Su opinión era que si no había otro remedio, se legalizara el pago a plazos y así nadie sacaría beneficio personal al permitir las dilaciones ilegales de esos cobros.

A continuación vinculaba el mismo tema de las almonedas con los tributos, argumentando que otra medida contra esos abusos, y que además mejoraría el trato dado a los indígenas, era mandar que esos tributos fueran cargados por éstos sólo hasta la ciudad, villa o minas de españoles más cercanas y allí se subastaran o vendieran al menudeo, remitiendo luego los alcaldes mayores, los corregidores o sus tenientes el pago a los oficiales reales. Incluso completaba su opinión con una crítica a esas autoridades locales escribiendo:

“... y ansi dará vuestra magestad en qué entender a las tales justicias pues llevan vuestro real salario, porque hay muchos corregidores y tenientes que llevan salario y no saben adónde es el cargo que les dieron si no es cuando van a dar residencia, porque los tornen a proveer sin haber administrado en justicia ninguna y no son pocos; ...". ${ }^{39}$

Triguillos de Silva extendía sus denuncias a la picaresca de sectores cualificados como los encomenderos, a los que acusaba de quejarse continuamente por la bajada de sus tributarios y pedir otras ayudas, sin indicar que desde mediados del siglo XVI los precios habían tenido una subida tan fuerte que ellos seguían cobrando lo mismo y engañaban al Consejo de Indias para seguir viviendo con lujo.

Al contrario que el relator Francisco de Morales, otra cuestión que le preocupaba era la disminución de la cantidad de tierras realengas en la Nueva España, debido a que gentes como "un oficial barbero, herrero, calderero y de otros oficios y hombres viles que no son labradores ..." habían obtenido de los virreyes y oidores mercedes de estancias y caballerías de tierra, que luego revendieron al contado o pusieron a censo en cuanto tuvieron la carta acordada, sacando con ello grandes beneficios. Por eso opinaba con dureza:

“... es una burla burlada lo que se ha hecho y se hace, qué cosa es esto que siendo vuestra la tierra y adquirida con vuestra real hacienda y sustentada con escuadrones de gente en los campos para tenella en paz y en concordia y con vuestras justicias,

39 Carta de 15 de marzo. Ibidem, pág. 183. 
administrando y con mucha costa de vuestra real hacienda, ... que haya un desafuero y que estén todos tan ciegos que no quieran avisar lo que conviene al pro de vuestra real hacienda, sino que todos sean usurpadores y robadores de vuestra majestad, ...". ${ }^{40}$

Como remedio mínimo proponía que todos los propietarios de tierras fueran obligados a empadronarse antes de pagar sus impuestos por esa posesión, con lo cual la Corona conseguiría algún beneficio de esas mercedes dadas en perjuicio de sus tierras y el que no lo cumpliera, sería desposeido para que esos terrenos se pasasen a gente pobre y trabajadora dispuesta a cultivarlos.

De todos los informantes estudiados, éste es el único que se refiere a las mujeres y, por supuesto, lo hace desde un enfoque económico, al ver a las solteras indígenas como posibles sujetos tributarios, comparándolas con las de diversas regiones de la metrópoli que, cuando se dedicaban al comercio o al trabajo asalariado, pagaban impuestos. Según Triguillos de Silva, en la Nueva España había en esas fechas de la segunda mitad del siglo XVI hasta "un millón y más" de mujeres solteras que podían tributar, ya que conseguían grandes ganancias en los mercados, actuando allí "con más fuerza y más varonilmente". Daba la cifra a pagar de seis reales anuales, distribuidos a medio real por mes, añadiendo que eso no supondría para ellas una carga excesiva ya que ganaban al menos de 15 a 30 pesos cada año.

Su afán casi obsesivo por aumentar las rentas del erario público le llevó a extender la propuesta de incluir también entre los tributarios a los "mozuelos de diez hasta quince años", a los que cifraba en más de cien mil, alegando que con esas edades ya se alquilaban para servicios varios, incluyendo los obrajes y su duro trabajo, con lo que llegaban a ganar de doce a dieciseis reales al mes y un tributo de medio real mensual no sería gravoso para ellos. Queda claro que, para este informante lleno de iniciativas, ninguna persona de raza indígena que trabajara debía quedar exenta de tributar.

La parte final de la segunda carta la dedicó al tema de la venta de oficios, que empezaba a verse como una fuente oficial de ingresos. Describe Triguillos de Silva que los procuradores de la Real Audiencia de México ya vendían ilegalmente su cargo desde hacía años. Por eso proponía, sin ninguna duda, que fuera la Corona la que ofertase puestos diversos como procurador, fiel ejecutor y otros vinculados a los Cabildos, escribanos del crimen, jueces de difuntos, etc., con el fin de conseguir ingresos extraordi-

40 Ibidem, pág. 185. Obsérvese que en este corto párrafo aparece tres veces citada la Real Hacienda, como una clara muestra de la preocupación del corresponsal por el erario público. 
narios. Como sabemos gracias a las publicaciones de Francisco Tomás y Valiente y otros, ${ }^{41}$ las ventas serían una fórmula usual desde esos años del siglo XVI, sin que eso signifique una atención directa a esta sugerencia del funcionario de la Real Hacienda aquí comentado.

\section{Comentario final}

Haciendo un recuento temático de estas misivas, se ven varios bloques:

-El fomento económico.- Todos se preocupan de aspectos relacionados con el desarrollo de la agricultura especializada (plantas tintóreas, vides, olivos, especias y plantas medicinales), la vigilancia de la ganadería extensiva y suelta y sus dueños sin título de propiedad, el impulso de las industrias derivadas como la fabricación de cerveza y diversas telas y, por supuesto, la minería de plata, con los problemas derivados de la amonedación como la salida excesiva de moneda con destino a la metrópoli o la necesidad de mezclarla con otros metales para obtener la Corona un mayor beneficio. Un tema que tratan varios con detalle es la carestía, vinculada al abastecimiento y a las cuestiones tributarias.

- Los problemas sociales. - Ambientados en la cambiante realidad novohispana de mediados del siglo XVI, se refieren tanto a los indígenas como a los españoles. Los primeros son vistos contradictoriamente, ya que se defiende la conservación de su organización precortesiana (autoridades, formas de vida) en una república separada pero, al mismo tiempo, se les ve como trabajadores en las minas y como sujetos tributarios.

Respecto a los españoles, se recogen: las reivindicaciones de conquistadores y encomenderos (aunque Triguillos de Silva acuse a éstos últimos de engaño); las dificultades derivadas de la aplicación de las Leyes Nuevas y de las demandas para que se realice de una vez el reparto general de la tierra entre ellos. El caballero León Romano anuncia la inestabilidad social que va a suponer la primera generación criolla, todavía adolescente en 1550 .

- Críticas sobre los diversos poderes. - Abundan las referidas a las autoridades locales como alcaldes mayores, corregidores y sus tenientes, así como las que denuncian problemas relacionados con la administración

41 Tomás y Valiente, F.: La venta de oficios en Indias (1492-1606). Madrid, 1972. 
de justicia y el comienzo de las ventas de oficios públicos para el beneficio de la Real Hacienda. Varios expresan duras opiniones contra los miembros de las órdenes religiosas, considerando que manipulan a los indígenas aprovechando su poder sobre ellos.

Estos corresponsales se muestran de acuerdo en detallar las condiciones que debe reunir un buen gobernante de aquel territorio, al que la Corona tendrá que dar la mayor autonomía posible, pero también es común a todos la valoración de la tierra, para la que no ahorran adjetivos demostrando así su arraigo en ella, al mismo tiempo que su fidelidad al rey.

$$
* * *
$$

A través de estos hombres pueden verse, por tanto, las tensiones y posibilidades que México ofrecía a la vista, y a la pluma, de ellos. No cabe duda de que sus cartas debieron aportar noticias de interés a los gobernantes metropolitanos, quizás como contrapartida de la continua documentación oficial que llegaba al Consejo de Indias, aunque sea imposible valorar los efectos reales de sus variadas críticas y remedios. 